\title{
A sociological study of gender and astronomy in Spain
}

\author{
Eulalia Pérez Sedeño ${ }^{1 \star}$, Adriana Kiczkowski ${ }^{2}$ and Isabel Márquez Pérez $\left(^{3}\right.$
}

\begin{abstract}
The under-representation of women in science, technology, engineering and mathematics has been an issue of great concern within the European scientific community and beyond. To initiate actions that will alleviate this deficiency, it is important to understand the reasons behind it. This Perspective highlights the results of our research into the situation of women in the field of astronomy and astrophysics in Spain, which was first published in Spanish in 2010. In that study, we first summarized the situation of women astronomers in Spain on the basis of statistical data obtained from the most relevant Spanish institutions. Then we combined in-depth interviews with teaching staff and researchers that took place at the same time as the statistical survey. We also interviewed groups of PhD candidates and post-doctoral researchers to explore potential trends. Here we update the quantitative aspects of this analysis with more recent data from 2016, and present action plans already in place or recently proposed to improve the situation of women astronomers in Spain. We make this information available to the international astronomical community as motivation for further studies.
\end{abstract}

$\mathrm{n}$ Spain, astronomy as we understand it today started in the 1970s, with the generation that witnessed the installation of international observatories in both La Palma and Calar Alto. Spain also participated in programmes from the European Space Agency, of which it was a founding member. Astronomy in Spain has enjoyed a boom over the past few decades, as demonstrated for example by the construction and operation of the $10.4 \mathrm{~m}$ Great Telescope of the Canary Islands and its participation in the European Southern Observatory.

The increase in quantity and quality of Spanish astronomy is also demonstrated by the number of scientific publications gathered in the Web of Science: from about ten in 1973 to almost 900 in $2005^{1}$. In 2009, Spain was already the eighth largest contributor to publications in the field of space science, after the United States, Germany, England, France, Italy, Russia and Japan.

Crucial to the development of astronomy, astrophysics and planetary science in Spain were the successive National Plans of Scientific Research and Technological Development, the first of which was presented in 1988. In 2000, a specific national programme for astronomy and astrophysics was created with four fundamental objectives: basic research in astronomy and astrophysics, design and development of astronomical instrumentation, scientific exploitation of existing resources, and research and development in technologies related to astronomy.

On 8 March 2005, the Spanish government approved "measures to promote equality between women and men." These would be reinforced in the "Organic Law 3/2007 of March 22nd for real equality between women and men," usually referred to as the 'equality law'. In science and higher education, the law advocated equal treatment and equal opportunities in access to employment, vocational training and promotion, and working conditions. It also initiated the process of making the principle of equality mainstream in Spain.

There is a great body of work in academia on gender and gender science, especially in quantitative terms, all of which will be difficult to mention here. Such studies usually explore the situation in certain universities or areas, focusing on topics such as gender biases in assessment or peer review ${ }^{2}$, work-life imbalance ${ }^{3}$ or the pay gap ${ }^{4}$.
Generally speaking, one of the first attempts to analyse the situation of women in science was presented in 1994 by the Committee on Women in Science, Engineering and Technology, in the report named "The Rising Tide: A report on women in science, engineering and technology." However, it was a report from the European Technology Assessment Network that marked a true milestone in this type of work ${ }^{5}$. It presented, for the first time, statistical data for almost all the countries in the European Union. One of the first conclusions reached in the report was the need for gender equality statistics and indicators at all levels to be produced and published systematically. It proved difficult to obtain reliable data for comparison between the various member states. The report also examined the situation in other scientific institutions such as academies, quality and equity in the scientific professions or equity in peer review, and made a number of recommendations to European countries.

The first attempt to make a deep analysis of the situation of female astronomers in Spain was done within the core of activities carried out by the working group "She is an Astronomer" ("Ella es una astrónoma"), organized in Spain to mark the International Year of Astronomy 2009, for which it was presented as one of the cornerstone projects by the International Astronomical Union and UNESCO. That year the International Astronomical Union started to collect statistics about women astronomers ${ }^{6}$. In this context we began to analyse the situation of women astronomers in Spain. The objective was to paint an accurate picture of the situation of women in Spanish astronomy, based not only on statistical data from institutions that have a strong astronomy portfolio, but also on the protagonists' narratives. For this reason, our study combined quantitative and qualitative techniques, such as in-depth interviews and focus groups. The results were published in a book in Spanish ${ }^{7}$, which was the first sociological study for astronomy in Spain. Here we highlight some of the results of this study, update the numbers for 2016 to search for trends, and show implemented measures that have already been taken or have been proposed for the near future. Subsequently, some studies have been carried out on gender and astronomy ${ }^{8}$. 


\section{Spanish astronomers in 2009}

In 2002, a report from the Spanish Society of Astronomy (SEA) was published $^{9}$ in which some data, disaggregated by sex, served as a starting point for the study ${ }^{7}$.

For our quantitative study in 2009, we gathered data provided from a total of 46 institutions: 21 universities with specific astronomy or astrophysics departments; staff from 10 other universities that do not belong to a specialized department; eight research centres belonging to public research organizations (PROs); four observatories; and finally other institutions, such as one planetarium, the Laboratory of Spatial Astrophysics and Fundamental Physics, and the European Space Astronomy Centre, which we call 'others'.

In 2009, the number of people working in the fields of astronomy and astrophysics in Spain totalled 794, of which 70\% were men and $30 \%$ women (Poisson uncertainty $0.01 \%$ ). (Spanish statistics cover only these two categories and do not include non-binary gender expressions.) This is a much lower percentage compared with the mean of total researchers, considering that females made up $37.02 \%$ of all researchers in Spain in 2009. From this total of all astronomers, $46.5 \%$ worked in public administration, $38.7 \%$ in high school education and $34.1 \%$ in the Spanish Research Council (Consejo Superior de Investigaciones Científicas), the largest PRO.

The distribution of astronomers according to sex in the different institutions is shown in Fig. 1. The corresponding percentages are provided in Fig. 2, where it can be seen that among the institutions with the highest numbers - universities and PROs - the percentage of women was almost $30 \%$.

Female participation in the field increased considerably, from 112 in 2002 to 237 in 2009, although it remained much lower than in other fields. Nevertheless, only four women had the highest category of full professor (4/239), compared with 36/555 men. In the case of men, the number of $\mathrm{PhD}$ and post-doctorate fellows was quite similar (106 and 108), whereas for women the numbers were quite different (67 and 47). Here we see the same pattern as is observable in other fields: the number and percentage of women decrease at the senior levels of academic employment. This is known as the leaky pipeline problem ${ }^{5,10,11}$.

When comparing $\mathrm{PhD}$ fellows in universities and PROs desegregated by sex, there were more than twice as many men as women (51:22) in universities, while in PROs the ratio was nearly even (55:45) (Fig. 3a,b). The almost equal number of men and women PhD fellows in PROs may show that practically the same number of men and women apply for candidacy and their success is proportional to the number of applications. On the other hand, the large number of men professors at universities may encourage more men than women to study astronomy, and it is indicative of a glass ceiling $^{5}$. This disparity in representation highlights the need not only for women mentors, but also for men to become aware of their own unconscious biases and preferences, and to identify and support promising women candidates.

\section{Qualitative study of women astronomers in Spain in 2009}

The aim of the qualitative study was to go beyond the figures by presenting life stories. This could give us clues as to what might influence inequalities in the development of the professional careers of men and women in the field of astronomy. In addition, as another novel element we decided to interview both women and men to analyse and compare their discourse $\mathrm{e}^{12-14}$.

For the qualitative research stage we considered both the design and the results obtained in a 2003 study - the first to be carried out covering the whole of Spain ${ }^{15}$. One of the recommendations was to analyse the opinions of men astronomers. This would enable us to contrast and evaluate the respective professional trajectories and see in which aspects women and men researchers coincide and in which they differ, from both a professional and a personal point of view.

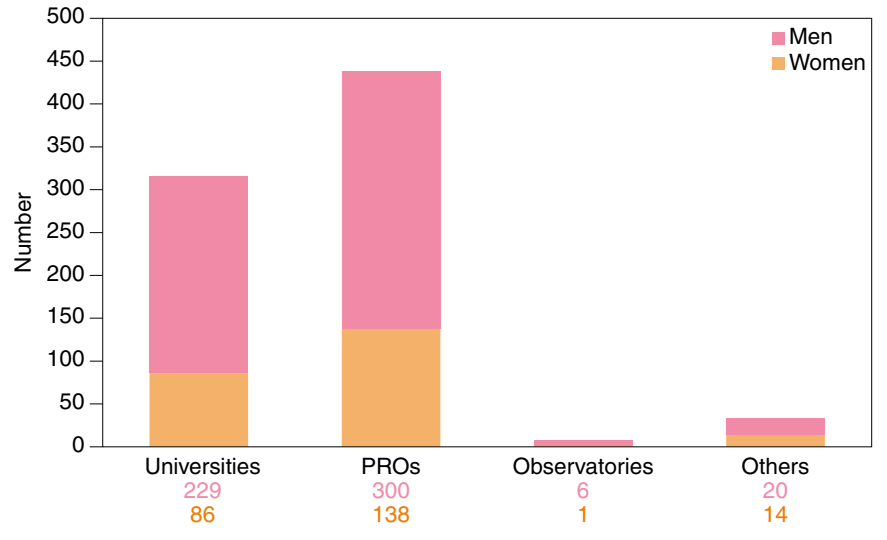

Fig. 1 | People working in astronomy (research and/or teaching) in Spain in 2009. Total numbers are provided for men (magenta) and women (orange). Different institutions are considered separately: Universities, PROs, observatories and others.

This part of the qualitative study was based on 14 in-depth interviews with teaching and research staff (eight women and six men) in universities and research institutions in Barcelona, Granada, La Laguna and Madrid, where the most important centres in astronomy are located. The criteria for choosing the interviewees were teaching and research experience, funded project management and decision-making positions. These were semi-structured interviews with an established script, but with complete freedom for interviewees to respond. The analysis was based on thematic axes that traced a temporal line coinciding with the main landmarks of their scientific and academic career (educational, professional and personal path), questions about the situation of astronomy in Spain, and remarks on the situation of women in science and technology.

We brought into play focus groups made up of younger people in $\mathrm{PhD}$ programmes and the post-doctoral phase. In this manner, we created a richer and more dynamic space for meeting, reflecting and sharing experiences. This provided us with broader general information and a larger number of opinions and contrasts. In practice, and as shown in the results, this turned out to be the right choice.

A total of six focus groups were created comprising 36 participants: 12 women and 12 men PhD candidate fellows (22-30 years old), and six women and six men post-doctorate researchers (3040 years old), from organizations in Barcelona, Granada and La Laguna.

The study revealed a clear and general opinion that, in recent years, an improvement in the working conditions of women astronomers had undoubtedly been observed, and that consequently severe imbalances and clear discrimination in different scientific areas had been overcome. There was also a nearly unanimous feeling that there were still some differences despite the advances, and that these differences should be resolved in the future. Often, the opinion was also expressed that general social change will improve women's professional standing and will, in particular, result in gender balance across all the institutions and professional strata in astronomy and astrophysics.

Despite the general impression of improvement, all participants pointed out that there was still some distance to go before full equality is reached. Inequality presents itself especially in higher strata or categories, in decision-making positions, and for those with political or management responsibility. Opinions gathered from the interviews and discussion groups showed that the reasons or causes that maintained the inequality, particularly at higher leadership levels, were not properly explained by the statistics. Situations of discrimination were not understood to be direct consequences of local processes occurring in the spheres to which the participants 


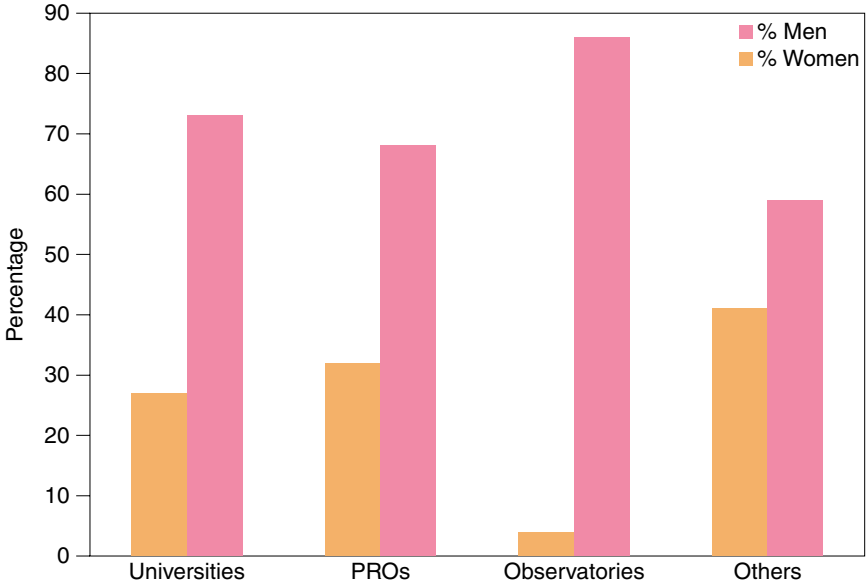

Fig. 2 | Percentage of women and men working in astronomy in 2009 in Spain. Different institutions are considered separately: universities, PROs, observatories and others. Colour scheme is the same as in Fig. 1.

belong or where they perform their activities. Respondents also disregarded the possibility that discrimination might be a function of specific actions in their close environment. Thus, even though this was not expressed explicitly, they took the view that internal discrimination did not result from direct discriminatory actions. For instance, maternity was considered a social aspect that is irrelevant to the profession; hence, if women decide to become mothers they must reconcile that with their work, and although they understood that this is difficult to achieve, they did not acknowledge any particular hindrance in the science and technology system.

On the other hand, there was the almost general conviction among both women and men, especially the youngest, that the current under-representation of women in astronomy was a logical consequence of an inherited feature because the number of women at universities is much lower than men. In this respect, it is important to highlight that women and men $\mathrm{PhD}$ fellows perceived that women's inequality forms part of Spain's past, and was thus irrelevant to their present lives and to their future and professional growth. Interestingly, younger men and women expressed at first that the problem of parity in university and in other spheres was already solved. A similar opinion was expressed among older generations, although it was mostly men who believed that equality was a solved problem, and that the situation was quite different from when they were students. In both age groups this visible improvement, which was only partial, tended to be taken as a supposedly definite solution of the problem. But after reflecting, they admitted that the issue was not resolved, and a justification then tended to appear. Interviewees, especially men, justified the situation by saying that things were on the right track and that because women have been incorporated into university courses, such natural growth will bring definite equality; it was simply a matter of time.

This belief is linked to another problem that appears as a basic axis of tension in the study: the nature of the mechanisms that maintain or reduce women's discrimination or inequality in scientific professions. In general, interviewees tended to believe that inequality has to do with processes of a global, external, social, political or ideological nature, embedded in the general structure of society, and that it therefore responds to mainstream social trends. Thus, discrimination in the academic or research sphere is a simple reflection of a larger situation. Many women in focus groups and interviews agreed initially that the difficulties are not motivated by direct actions related to individuals in the field of astronomy but, after further reflection, they began to perceive and point out firsthand experiences of discrimination, lack of interest, neglect and
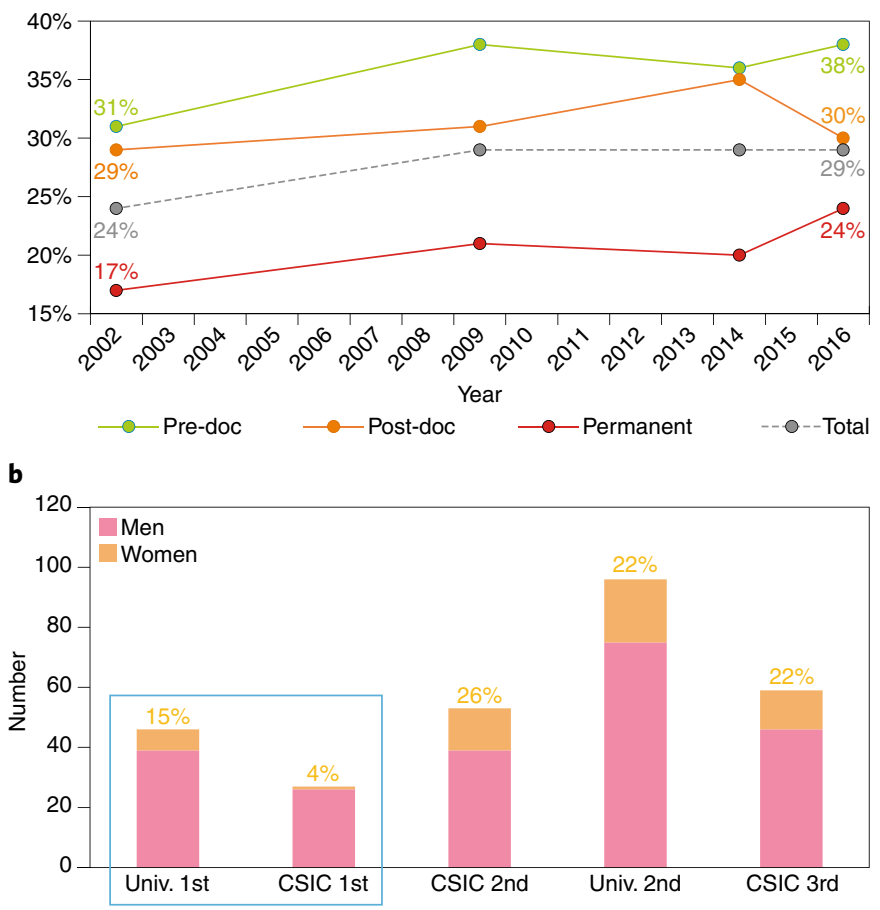

Fig. 3 | Percentage of women in research positions in astronomy in Spain. a, Time evolution, from the first study in 2002 to 2016. Colours show permanent positions (red), post-docs (orange), pre-docs (green) and total (dashed-grey). b, Permanent positions in 2016 for women (orange) and men (magenta). Different categories are shown separately: the blue box corresponds to those with the highest levels at universities (15\%) or research centres (4\%). Women with permanent positions at the lowest levels (Univ. 2nd and Consejo Superior de Investigaciones Científicas (CSIC) 3rd) are $22 \%$. The research centres have an intermediate level (with 26\%). Credit: reproduced from ref. ${ }^{16}$, SEA

lack of mechanisms with which to solve problems within the scientific community. They admitted that it had been challenging to situate themselves 'in a world of men'. In general, men interviewees resisted admitting that they may be acting - directly or indirectly - as discrimination agents themselves.

Beyond the ideas of those who maintain that discrimination is a problem already solved or that will be solved by a 'natural generational take-over', it is interesting to delve into the difference in perspectives regarding issues of social responsibility and ethics of care. From a woman's perspective, motherhood and family responsibilities are problems that she will have to face at some point of her personal life and that will have repercussions in her professional growth. 'Family' and emotional problems, childbearing, caretaking of children and the elderly, and household organization were rarely considered problems relating to the couple, but rather problems relating almost exclusively to women.

Men were reluctant to deal with personal or family factors during the interviews and group discussions. When asked about possible difficulties in combining professional life and private life, hardly any of them considered such problems as theirs, or at least they did not make this explicit. Those who seemed to be more aware of women's difficulties in this respect also affirmed that their jobs became 'important' and 'basic' pillars in the family organization, even when the female partner had similar opportunities for professional development.

It is important to emphasize that, especially among younger men, private life and its consequent emotional and family responsibilities were not considered to be a hindrance, difficulty or issue 


\section{Box 1 | Perception of gender inequality}

In the opinion of most men interviewees, the situation of women in science reflected that of society at large. The question of responsibility was dismissed as a matter that could be tackled individually; gender inequality was considered to be mainly a result of existing conditions in society and its norms; and internal discrimination was thought to be not produced by a series of direct actions. There was also resistance to accepting that the academic and research sphere may be a place in which social patterns are not only reproduced, but also generate specific mechanisms that perpetuate inequality.

that requires more or deeper analysis or reflection. This clearly contrasts with the opinions of younger women, both $\mathrm{PhD}$ candidates and post-doctorates, who brought up meaningfully their concern about reconciling work and personal life.

Labour instability in general was considered, by both young women and men, as one of the most problematic aspects in a scientific career. They are required to invest often more than ten years in education as 'interns' or fellows, without clear guarantees that they will reach long-term employment security. In the case of younger women, an additional uncertainty was implied: they believed that at some point in their professional careers they will have to choose between their personal and professional life, and even considered giving up their scientific career for emotional or personal reasons. In the case of men there was no such 'radical' consideration, because in most cases they did not express a priority in their preferences. Young men in general tended to believe that personal problems resulting from professional decisions or choices would not interfere negatively in their careers, or would at least be resolved favourably.

All collectives brought up the issue of preferential treatment policies or 'affirmative action', which tries to compensate for pre-existing unequal or uneven situations. Remarks and opinions revolved mostly around whether it is pertinent to create parity committees for staff evaluation and promotion. Opinions in this regard were not unanimous. On the one hand, it is rare to explicitly oppose parity commissions, except for isolated cases. However, from indirect criticisms presented specifically by men, we perceived their complete disapproval. As for women, opposition was minor but they highlighted the huge workload involved, given that the number of females in the profession is significantly lower than men, and therefore women see themselves as obliged to participate in this type of committee.

It is important to explain the policies and implementations of affirmative action, to avoid it being seen simply as a rule to be followed, with implementations based on a specific ideological option without detailed explanation. Active antidiscrimination policies therefore require constant guidance and argumentation so that everyone affected (men and women) understand their necessity

\section{Box 2 | Social responsibility and ethics of care}

All interviewees - women and men, young and old - believed that the caretaking of children or parents is a woman's direct responsibility. Women in general assumed such problems as their own, and men also felt it had to do exclusively with women. Men never presented personal issues as something related to their professional growth. Among younger men, private life and family responsibilities were not considered a hindrance, difficulty or issue that required reflection. In contrast, younger women brought up their concern about reconciling work and personal life as being significant.

\section{Box 3 | Scientific career versus personal life}

Young female interviewees believed that at some point in their professional career they would have to choose between their personal life and professional life, and had considered giving up their scientific career for emotional or personal reasons. Young men in general tended to believe that personal problems resulting from professional choices would not interfere negatively in their careers, or would at least be resolved favourably. Young men felt more secure as to their professional future than young women.

and future effectiveness. Without this type of social guidance, we believe that new forms of resistance and discrimination may arise unintentionally.

Likewise, men felt that women's presence in management and as leaders of institutions had an undercurrent that associated these types of activities with a desire to make one's way to the top. This approach was contradictory to the ethics of care and concern about others, which was thought to be a women's issue. The dichotomy of care/power and attribution of this polarity to women/men was detected in almost all interviews and fell into one pole or the other depending on gender: men were placed on a vertex of power at one extreme, with the opposite vertex of care populated mostly by women, with a huge range of variations in the middle that reflect tensions and contradictions. Additional insights from the interviews are provided in Boxes 1-4.

\section{Same numbers, new attitude}

To provide a general view on the international context of women in astronomy today, it is worth mentioning that the percentage of women astronomers affiliated with the International Astronomical Union (https://iauwomeninastronomy.org/statistics/iau-stats/ iau-member-statistics/) varies from $9 \%$ in India, Japan and The Netherlands to $28 \%$ in Ukraine. The average of $16 \%$ has not changed when considering only European countries. In Europe, Spain (20\%) is slightly above average, after Ukraine, Italy and France (Fig. 4). This number closely reflects that of women astronomers with permanent positions, since a certain level of seniority is required to enter the International Astronomical Union as a Spanish member.

The situation has not changed much in Spain over the past seven years (Fig. 5), with $29 \%$ of current astronomers being women $(210)^{16}$. The percentage of women with permanent positions $(24 \%)$ has been the same since 2009. That of post-docs was $30.3 \%$ in 2009 , but fell from $35 \%$ in 2014 to $30 \%$ in 2016 . Female PhD students were already at $38.7 \%$ in 2009 (Fig. 3a). As in other science, technology, engineering and mathematics disciplines, the glass ceiling effect is clearly noticeable, with a smaller percentage of women astronomers occupying the highest-level permanent positions at universities

\section{Box 4 | Affirmative action policies}

In the Spanish Research Council, the application of the Equality Law 2007 resulted in a clear improvement: in the six years during which the committees for the promotion of its permanent staff have been composed of equal numbers of women and men, the percentage of female research professors surpassed the ratio that universities had had over the past 22 years. Different types of criticism arise in general against affirmative actions, which try to compensate for pre-existing unequal or unbalanced situations. Most interviewees think of the legal measures taken as 'impositions' and 'decrees'. 


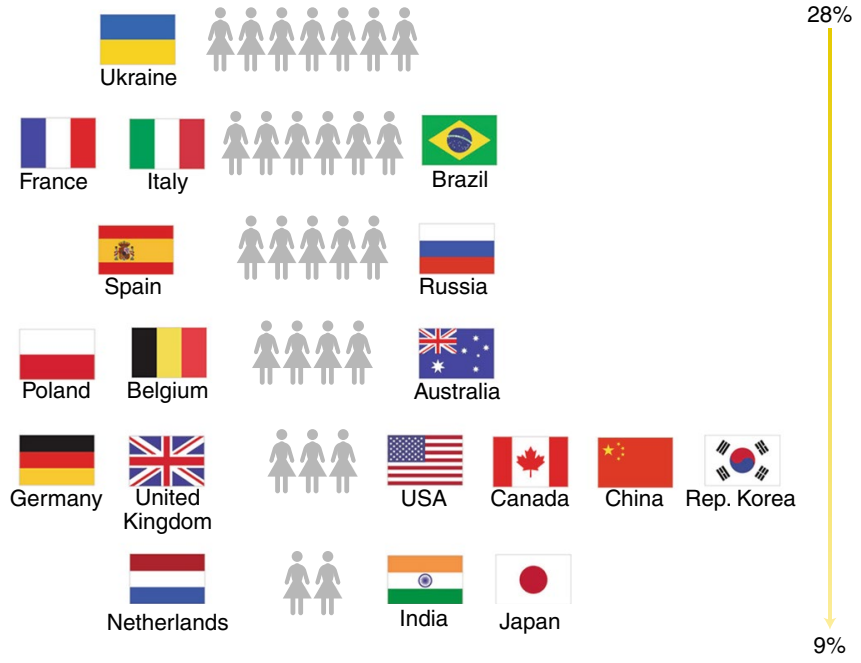

Fig. 4 | Percentage of women astronomers affiliated with the International Astronomical Union in 2017. Only countries with more than 150 members are shown. European countries are shown to the left. The different rows show percentages from a maximum of $28 \%$ (Ukraine) to a minimum of 9\% (The Netherlands, India and Japan). Numbers were taken from the International Astronomical Union (https://www.iau.org/administration/ membership/individual/distribution/). Credit: Flag images, Vermicule / Alamy Stock Vector

(15\%) and a much smaller percentage in research centres (4\%) with respect to basic levels (22\%) (Fig. 3b).

The 2010 constitution of the Committee for Women and Astronomy of the Spanish Astronomical Society (WA-SEA) states its commitment to present reports, on a yearly basis, that show ancillary statistics (for instance, the percentage of research projects led by women and their financial support) to draw a more detailed picture of the situation of women astronomers in Spain. The WA-SEA is also committed to presenting, at every SEA scientific meeting, the success rates for women and men asking for oral contributions, the percentage of women among invited reviews and that of women chairs on the different panels. Having endorsed the International Astronomical Union resolution B4 on supporting women in astronomy, WA-SEA aims at "promoting gender equality and empowering women," and encourages the members of the SEA to "break down barriers and ensure that men and women are given equal opportunities to pursue a successful career in astronomy at all levels and career steps." The production of annual statistics helps to monitor eventual changes and quantify the impact of this and other supportive actions. The main activities at the start of the committee were to promote and collaborate in creating the sociological study presented here, while also making female astronomers, from both Spain and abroad, visible to Spanish researchers in astronomy and to the general public. For these goals, several projects were developed. A calendar on "Women astronomers who made history" was produced to highlight twelve exceptional women from different epochs and countries, whose contributions to the advancement of science deserve to be lifted out of anonymity and into a place in history. "Women in the stars" was a series of eight TV programmes devoted to the contribution of Spanish women astronomers, made in collaboration with the Spanish National Distance Education University. The exhibit "She Astronomer" was aimed at teaching astronomy from a new perspective, that of the relevant contributions made by women astronomers from different times and places. A website displaying women astronomers who have received prizes and recognition was set up in 2009 (http://www.sea-astronomia.es/ drupal/mujer; most of the material is in Spanish, but there is a sub-

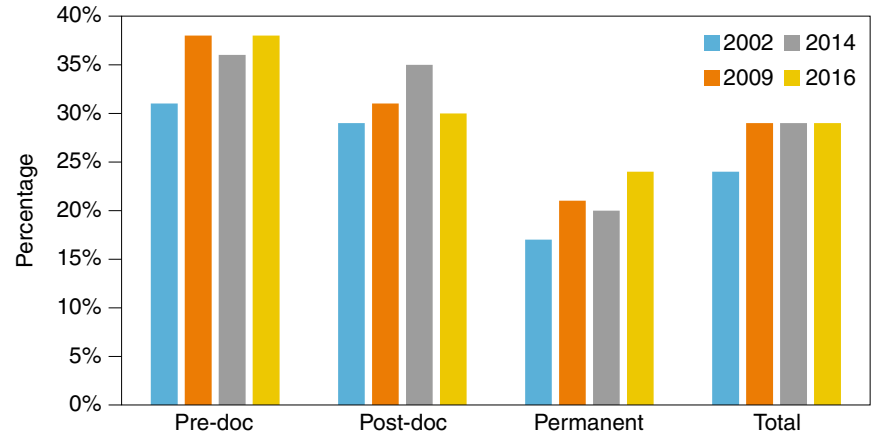

Fig. 5 | Percentage of women astronomers in Spain from 2002 to 2016. Data are available for 2002 (blue), 2009 (orange), 2014 (grey) and 2016 (yellow). For any year, the highest percentage is among pre-doctoral researchers ( $>35 \%$ since 2009), less for post-doctoral researchers (around $30 \%$ ) and lowest for permanent staff ( $>20 \%$ ). The average percentage for all categories has remained the same (29\%) from 2009 to 2016.

titled version of the videos "Mujeres en las estrellas" and an English version of the exhibition panels "Con A de astrónomas"). But the action that is expected to have a deeper impact on the Spanish Astronomical Society is the recent implementation of the WA-SEA Equality Plan (https://www.sea-astronomia.es/drupal/sites/default/ files/archivos/PlanIgualdadSEA.pdf), which was approved by the General Assembly in 2016. This plan includes a number of specific measures to support women in choosing a research career, promote equality of opportunities in their access and professional progression, encourage equality of incentives and resources for men and women, facilitate professional and family reconciliation, and ensure the participation of women in management committees and scientific forums. The Equality Plan defines the WA-SEA as an advisor to the SEA on issues of gender equality, and also as the entity responsible for planning and coordinating equality issues in the SEA. WA-SEA is committed to monitoring progress in achieving objectives, with collaboration from the SEA council, and receiving possible complaints from SEA members regarding discriminatory practices related to gender (for example, inequality in the allocation of observation times, or under-representation of women as key speakers in congresses). The objectives achieved and the impact of the Equality Plan will be analysed at two-year intervals, with the corresponding results providing the basis for future reviews. The implementation of this plan, endorsed by the entire SEA community, reflects a new attitude in the sense that, even if inequality issues have not disappeared, there is a common recognition and an overall wish to improve the situation by promoting vocations among women and increasing their visibility (for instance by presenting them for national and international awards).

The implementation in 2019-2020 of a new sociological study - beginning ten years after the study in 2009 - will be one way for the WA-SEA to probe possible evolutions in perception of the main differential difficulties that men and women face in their research on astronomy. It will be particularly interesting to follow up on the careers of those who were just starting in 2009. This could be illuminating when it comes to explaining the direct effects of established, specific social and cultural conditions affecting women that may have a negative impact on their careers.

Data availability. The data that support the plots within this paper and other findings of this study are available from the corresponding author upon reasonable request.

Received: 13 November 2017; Accepted: 1 June 2018; Published online: 30 July 2018 


\section{References}

1. Barcons, X. \& Rodrigo, R. El espectacular auge de la astronomía en España. Árbor CLXXXIII, 705-719 (2007).

2. Weneras, C. \& Wold, A. Nepotism and sexism in peer review. Nature 387, 341-343 (1997).

3. Hilton, D. Practical policies can combat gender inequality. Nature 523, 7 (2015). 2 July.

4. National Research Council. Gender Differences at Critical Transitions in the Careers of Science, Engineering, and Mathematics Faculty (National Academies Press, 2010).

5. Science Policies in the European Union: Promoting Excellence through Mainstreaming Gender Equality (European Commission, Brussels, 2000).

6. Cesarsky, C. \& Walker, H. Head count: statistics about women in astronomy. Astron. Geophys. 51, 2.33-2.36 (2010).

7. Pérez Sedeño, E. \& Kiczkowski, A. Un Universo por Descubrir. Género y Astronomía en España (Plaza y Valdés, 2010).

8. Nature Astronomy Focus: Gender Equity in Astronomy. https://www.nature. com/collections/wmzzzfjpyz (2 June 2017).

9. Barcons, X. et al. Informe sobre el Estado de la Investigación en Astronomía en España (1999-2001) [in Spanish] (Sociedad Española de Astronomía, 2002); http://diposit.ub.edu/dspace/bitstream/2445/46689/1/508983.pdf.

10. Alper, J. The pipeline is leaking women all the way along. Science 260, 409-411 (1993).

11. Pell, A. Fixing the leaky pipeline: Women scientists in academia. J. Anim. Sci. 74, 2843-2848 (1996).

12. Denzin, N. K. \& Lincoln, Y. S. (eds) Handbook of Qualitative Research (Sage, 1994).
13. Merton, R. K. \& Kendall, P. The focused interview and focus groups. Continuities and discontinuities. Public Opin. Quart. 5, 550-556 (1956).

14. Kvale, S. InterViews: An Introduction to Qualitative Research Interviewing (Sage, 1996).

15. Pérez Sedeño, E. et al. Situación de las Mujeres en el Sistema Educativo de Ciencia y Tecnología en España y su Contexto Internacional [in Spanish] (Consejo Superior de Investigaciones Científicas (CSIC), 2003); http://www. csic.es/web/guest/informes-precedentes1.

16. Gorgas, J. et al. Segundo Informe de los Recursos Humanos en Astronomía y Astrofísica en España [in Spanish] (Sociedad Española de Astronomía, 2016); http://www.sea-astronomia.es/drupal/sites/default/files/archivos/ informe_2016_v1.pdf.

\section{Author contributions}

E.P.S. took the lead in writing the manuscript. A.K. performed all interviews. I.M.P. made the figures. All authors provided critical feedback and helped shape the content of the manuscript.

\section{Competing interests}

The authors declare no competing interests.

\section{Additional information}

Reprints and permissions information is available at www.nature.com/reprints.

Correspondence should be addressed to E.P.

Publisher's note: Springer Nature remains neutral with regard to jurisdictional claims in published maps and institutional affiliations. 